\title{
Annual Report on the External Quality Assessment Scheme for Clinical Chemistry in Korea (2014)
}

\author{
Sun Hee Jun and \\ Junghan Song, as \\ Clinical Chemistry \\ Subcommittee, The \\ Korean Association \\ of External Quality \\ Assessment Service \\ Department of Laboratory \\ Medicine, Seoul National \\ University Bundang \\ Hospital, Seoul National \\ University College of \\ Medicine, Seongnam, Korea
}

\begin{abstract}
The Clinical Chemistry subcommittee of The Korean Association of External Quality Assessment Service conducted external quality assessments in 2014. This included general chemistry and blood gas measurements as part of a scheme of six trials, comprising of three samples each. All control materials were sent at the same time. The overall response rates were $93.4 \%$ for general chemistry and $90.0 \%$ for blood gas. The parameters tested included sodium, potassium, chloride, blood urea nitrogen, glucose, calcium, phosphorus, uric acid, creatinine, bilirubin, total protein, albumin, total cholesterol, triglyceride, AST, ALT, alkaline phosphatase, lactate dehydrogenase, gamma glutamyl transferase, HDL cholesterol, and LDL cholesterol for general chemistry and $\mathrm{pH}$, partial pressure of carbon dioxide, and partial pressure of oxygen for blood gas assessment. Two types of reports were generated, namely, a method summary report including mean, standard deviation, and coefficient of variation, for each test method, as well as a result summary report of each participating laboratory, including mean, standard deviation, number of peer groups, and standard deviation index and variance index scores of each laboratory. The overall quality performance in 2014 was similar to that of previous years and as compared to results from 2013, the inter-laboratory variation was lower. The requisite continual improvement in the quality of clinical chemistry testing can be achieved through participation in similar proficiency testing programs.
\end{abstract}

(J Lab Med Qual Assur 2015;37:115-123)

Key Words: Laboratory proficiency testing, Clinical chemistry
Corresponding author: Junghan Song

Department of Laboratory

Medicine, Seoul National University Bundang Hospital, Seoul National University College of Medicine, 82 Gumiro 173beon-gil, Bundang-gu, Seongnam 13620, Korea Korea Tel: +82-31-787-7691

Fax: $+82-31-787-4015$

E-mail: songjhcp@snu.ac.kr

pISSN: $2384-2458$

eISSN: 2288-7261

\section{서론}

대한임상검사정도관리협회는 1976년 8월 21일 창립되어 1977 년도에 39 개 병원의 검사실을 대상으로 검사실간 신빙도 조사를 국내에서 처음으로 실시하였다. 임상화학분과위원회 는 1980년도에 발족되어 일반화학검사 및 혈액가스검사에 대 한 신빙도조사사업을 담당해 오다가[1-3], 2008년부터 당화혈
색소에 대한, 2012년부터는 지질 및 크레아티닌에 대한 정확 도 기반 신빙도조사를 추가로 해오고 있다[4]. 저자들은 2014 년 실시되었던 일반화학검사 및 혈액가스검사에 대한 신빙도 조사사업 결과를 분석하여 보고하고자 한다. 


\section{재료 및 방법}

\section{1. 대상}

2014년에도 예년과 마찬가지로 일반화학검사는 4회, 혈액 가스검사는 2 회에 걸쳐 회차당 3 개의 검체에 대해 신빙도조사 를 시행하였다. 정도관리물질의 발송은 일반화학 12 종, 혈액 가스 6종을 특수 제작한 용기에 넣어 일괄적으로 한 번에 발송 하였다. 물질의 발송은 첫 분석 시작 약 한 달 전에 일반화학 1,310 기관, 혈액가스 480 기관에 12 회분을 동시에 발송하였고 추가로 가입하는 기관이 발생함에 따라 4월에 21기관, 6월에 15 기관, 9 월에 9 기관에 검체를 추가 발송하였다.

\section{2. 정도관리물질과 검사종목}

일반화학 정도관리물질은 BioRad사의 Lyphocheck Assayed Chemistry (Bio-Rad Laboratories, Hercules, CA, USA), Randox사의 Human Precision (Randox Laboratories, Crumlin, UK)과 Roche사의 Precinorm U, Precipath U (Roche Diagnostics, Basel, Switzerland)와 같 이 사람 혈청 기본의 제품을 사용하였다. 혈액가스 정도관리물 질은 BioRad사의 Liquicheck (Bio-Rad Laboratories) 제품 을 사용하였다(Table 1).
검사종목은 일반화학검사로 2013년까지 전해질, 단백, 지 질, 효소검사 등 19종목이었지만[5] 다수의 기관에서 $\mathrm{HDL}$ 및 LDL 콜레스테롤 항목의 추가요청이 있어 2014년에는 이 항목을 포함하여 21종목을 시행하였고 혈액가스검사는 $\mathrm{pH}$, partial pressure of carbon dioxide $\left(\mathrm{pCO}_{2}\right)$, partial pressure of oxygen $\left(\mathrm{pO}_{2}\right)$ 3종으로 전년도와 동일하였다[5]. 미리 정해 진 검사시행일로부터 약 10 일간 결과입력기간을 지정하여 대 한임상검사정도관리협회 홈페이지에 결과와 검사방법 등을 입력하도록 하였다.

\section{3. 결과 판정 및 분석}

2011년도부터 일반화학의 신빙도조사 결과분석은 각 기관 이 홈페이지에 항목별 검사방법과 결과를 입력하게 되면 평가 일 이후에 홈페이지에서 내에서 자동으로 방법별 통계분석자 료와 기관별 통계분석자료가 보고되도록 하였다. 방법별 통계 분석자료에는 검사종목별로 검사방법에 따른 평균, 표준편차, 변이계수(coefficient of variation)가 포함되어있고, 기관별 통 계분석자료에는 각 기관의 항목별 평균, 표준편차, 동일방법 참가기관 수, 표준편차지수(standard deviation index), 동일 방법군별(peer group) 변동지수점수법(variance index score, VIS)과 각 항목별 누적 VIS의 분포도가 포함되어 있다. 이때

Table 1. Control material provided for analysis, test due dates, and response rates from the trials in 2014

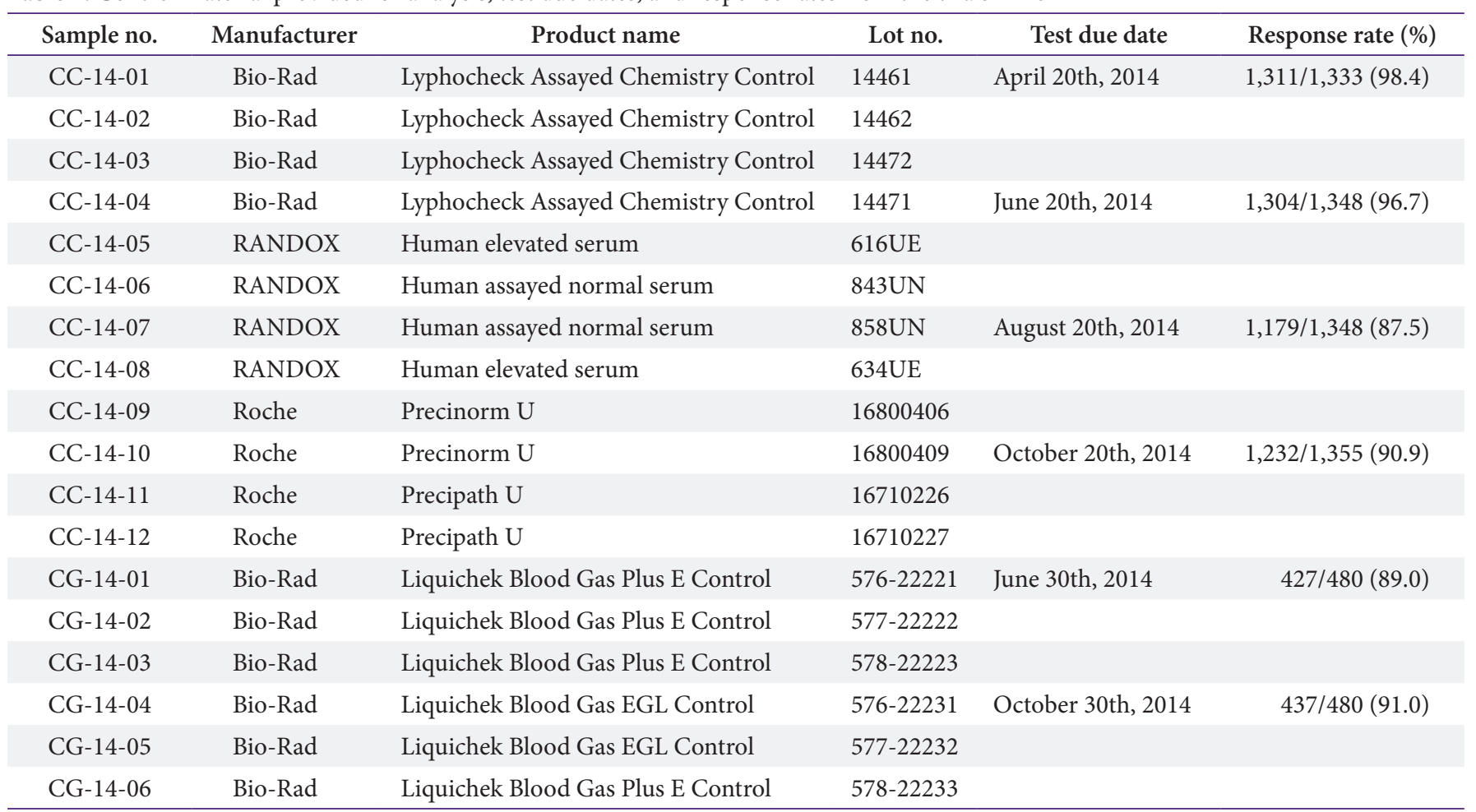

Bio-Rad Laboratories, Hercules, CA, USA; Randox Laboratories, Crumlin, UK; Roche Diagnostics, Basel, Switzerland. 
Journal of LABORATORY MEDICINE and QUALITY ASSURANCE

Sun Hee Jun et al • Annual Report of the K-EQAS for Clinical Chemistry (2014)

각각의 분석에서 2011 년도까지는 \pm 3 표준편차 이상의 값을 배제한 후 평균과 표준편차를 재계산하였지만, 2012년도부터 \pm 2 표준편차 이상의 값을 배제한 후 재계산한 평균과 표준편 차 값을 기준으로 사용하였다. 혈액가스의 경우 2012년부터 기기회사와 기기별로 분류하여 peer group을 좀 더 세분화하 였고, 5 기관 미만은 평균, 표준편차, 변이계수 등을 보고하지 않았다.

\section{결과 및 고찰}

일반화학과 혈액가스의 정도관리물질의 배송에 있어서는 당 해 연도 초에 일괄적으로 보내고 그 후 추가로 가입하는 기관 에 물질을 발송하고 있어, 회차마다 물질을 보낸 기관수가 약 간씩 다르게 된다. 그에 따라 응답률도 회차마다 달라지므로 매 회차의 응답률을 계산하여 평균을 내었다(Tables 1, 2).
2014년도 일반화학의 경우 총 1,355 기관에 정도관리물질을 발송하여 평균 회신율이 $93.4 \%$ 로 2013년도의 $90.8 \%$ 보다 약 간 높아졌다[5]. 혈액가스의 경우도 총 480개 기관에 정도관 리물질을 발송하였는데 평균 회신율이 $90.0 \%$ 로 2013년도의 $88.0 \%$ 보다 약간 높아졌다(Table 1).

각 검사항목별 주요 측정방법의 분포는 Table 3에 정리하였 다. 각 기관의 검사방법은 2013년도와 비교하였을 때 별다른 변화를 보이지는 않았다. 소디움 등 전해질 검사방법은 참가 기관의 $97 \%$ 이상이 ion-selective electrodes 방법을 사용하고 있고, 혈당 검사방법은 참가기관의 $71 \%$ 이상이 hexokinase 방법을 사용하고 있었다[5]. 총 콜레스테롤은 참가기관의 $98.1 \%$ 가 효소법을 사용하고 있었다. 크레아티닌 검사방법은 대부분 Jaffe kinetic 방법을 사용하고 있으나 $3.72 \%$ 의 기관 등에서 시약이 고가이기는 하나 picric acid를 사용하지 않는 효소법을 사용하고 있었다. Bilirubin과 triglyceride는 가장

Table 2. Number of laboratories that responded for each test in 2014

\begin{tabular}{|c|c|c|c|c|c|c|c|c|c|c|c|c|}
\hline \multirow{2}{*}{ Test } & \multicolumn{12}{|c|}{ Sample no. } \\
\hline & $14-01$ & $14-02$ & $14-03$ & 14-04 & $14-05$ & $14-06$ & $14-07$ & $14-08$ & 14-09 & $14-10$ & $14-11$ & $14-12$ \\
\hline Sodium & 845 & 845 & 845 & 835 & 833 & 834 & 779 & 779 & 779 & 802 & 802 & 802 \\
\hline Potassium & 845 & 845 & 845 & 835 & 833 & 834 & 779 & 779 & 779 & 802 & 802 & 802 \\
\hline Chloride & 829 & 829 & 829 & 819 & 817 & 818 & 764 & 764 & 764 & 787 & 787 & 787 \\
\hline Blood urea nitrogen & 1,248 & 1,248 & 1,248 & 1,240 & 1,239 & 1,239 & 1,129 & 1,129 & 1,127 & 1,173 & 1,173 & 1,173 \\
\hline Glucose & 1,277 & 1,277 & 1,277 & 1,281 & 1,279 & 1,279 & 1,163 & 1,162 & 1,160 & 1,212 & 1,212 & 1,212 \\
\hline Total calcium & 644 & 644 & 644 & 638 & 637 & 637 & 607 & 607 & 607 & 620 & 620 & 620 \\
\hline Phosphorus & 602 & 602 & 602 & 597 & 597 & 597 & 568 & 568 & 568 & 582 & 582 & 582 \\
\hline Uric acid & 1,078 & 1,078 & 1,078 & 1,062 & 1,062 & 1,062 & 972 & 971 & 970 & 1,012 & 1,012 & 1,012 \\
\hline Creatinine & 1,291 & 1,290 & 1,291 & 1,283 & 1,283 & 1,282 & 1,165 & 1,164 & 1,162 & 1,215 & 1,215 & 1,215 \\
\hline Total bilirubin & 1,219 & 1,219 & 1,219 & 1,209 & 1,208 & 1,208 & 1,102 & 1,101 & 1,099 & 1,147 & 1,147 & 1,147 \\
\hline Total protein & 1,213 & 1,213 & 1,212 & 1,203 & 1,203 & 1,203 & 1,099 & 1,098 & 1,096 & 1,143 & 1,143 & 1,143 \\
\hline Albumin & 1,221 & 1,221 & 1,221 & 1,210 & 1,210 & 1,210 & 1,106 & 1,105 & 1,103 & 1,151 & 1,151 & 1,151 \\
\hline Total cholesterol & 1,293 & 1,293 & 1,292 & 1,285 & 1,285 & 1,285 & 1,166 & 1,166 & 1,164 & 1,217 & 1,217 & 1,216 \\
\hline Triglyceride & 1,272 & 1,272 & 1,272 & 1,263 & 1,263 & 1,263 & 1,148 & 1,148 & 1,146 & 1,195 & 1,195 & 1,195 \\
\hline AST & 1,308 & 1,308 & 1,308 & 1,301 & 1,301 & 1,301 & 1,177 & 1,177 & 1,175 & 1,231 & 1,231 & 1,231 \\
\hline ALT & 1,309 & 1,309 & 1,309 & 1,302 & 1,302 & 1,302 & 1,178 & 1,178 & 1,176 & 1,232 & 1,232 & 1,232 \\
\hline Alkaline phosphatase & 1,175 & 1,174 & 1,174 & 1,163 & 1,162 & 1,161 & 1,065 & 1,065 & 1,065 & 1,104 & 1,103 & 1,103 \\
\hline Lactate dehydrogenase & 866 & 866 & 866 & 861 & 861 & 861 & 799 & 799 & 799 & 821 & 821 & 821 \\
\hline Gamma glutamyl transferase & 1,279 & 1,279 & 1,278 & 1,271 & 1,270 & 1,270 & 1,154 & 1,154 & 1,152 & 1,204 & 1,204 & 1,204 \\
\hline HDL cholesterol & 1,046 & 1,046 & 1,046 & 1,085 & 1,084 & 1,085 & 1,013 & 1,013 & 1,010 & 1,055 & 1,055 & 1,055 \\
\hline LDL cholesterol & 719 & 719 & 719 & 730 & 730 & 730 & 699 & 699 & 699 & 713 & 713 & 713 \\
\hline $\mathrm{pH}$ & 427 & 427 & 427 & 437 & 437 & 437 & - & - & - & - & - & - \\
\hline Partial pressure of carbon dioxide & 427 & 427 & 427 & 437 & 437 & 437 & - & - & - & - & - & - \\
\hline Partial pressure of oxygen & 427 & 427 & 427 & 437 & 437 & 437 & - & - & - & - & - & - \\
\hline
\end{tabular}


Journal of LABORATORY MEDICINE and QUALITY ASSURANCE

Sun Hee Jun et al • Annual Report of the K-EQAS for Clinical Chemistry (2014)

Table 3. Analytical methods used for clinical chemistry (\%)

\begin{tabular}{|c|c|c|c|}
\hline \multirow{2}{*}{ Item } & \multirow{2}{*}{ Analytical method } & \multicolumn{2}{|c|}{ Year } \\
\hline & & 2013 & 2014 \\
\hline \multirow{6}{*}{$\begin{array}{l}\text { Sodium/ } \\
\text { potassium }\end{array}$} & Flame photometry & 0.37 & 0.24 \\
\hline & ISE indirect & 54.17 & 55.03 \\
\hline & ISE direct & 42.71 & 42.37 \\
\hline & Enzymatic & 0.37 & 0.47 \\
\hline & Colorimetry & 0.25 & 0.00 \\
\hline & Other & 1.74 & 1.66 \\
\hline \multirow[t]{5}{*}{ Chloride } & Coulometric-amperometry & 0.13 & 0.00 \\
\hline & ISE indirect & 54.30 & 55.37 \\
\hline & ISE direct & 43.04 & 42.34 \\
\hline & Enzymatic & 0.25 & 0.36 \\
\hline & Others & 1.90 & 1.69 \\
\hline \multirow[t]{6}{*}{$\begin{array}{c}\text { Blood urea } \\
\text { nitrogen }\end{array}$} & $\begin{array}{l}\text { Urease with glutamate } \\
\text { dehydrogenase }\end{array}$ & 96.83 & 96.31 \\
\hline & Urease-indophenol & 0.84 & 0.72 \\
\hline & Urease hydrolysis & 0.08 & 0.00 \\
\hline & Urease quinolinium dye & 0.93 & 0.88 \\
\hline & Conductivity rate & 0.59 & 0.56 \\
\hline & Others & 1.10 & 1.28 \\
\hline \multirow[t]{6}{*}{ Glucose } & GOD, peroxidase, colorimetry & 22.44 & 23.57 \\
\hline & GOD- $\mathrm{O}_{2}$ consumption & 0.67 & 0.63 \\
\hline & Hexokinase, G6PD, UV & 72.98 & 71.89 \\
\hline & Hexokinase, G6PD, colorimetry & 0.91 & 0.55 \\
\hline & Glucose dehydrogenase & 1.08 & 1.33 \\
\hline & Others & 1.50 & 1.96 \\
\hline \multirow[t]{4}{*}{ Phosphorus } & Phosphomolybdate, reduction & 25.26 & 24.58 \\
\hline & Phosphomolybdate-UV & 73.88 & 74.42 \\
\hline & Enzymatic method & 0.00 & 0.00 \\
\hline & Others & 0.86 & 1.00 \\
\hline \multirow[t]{6}{*}{ Calcium } & O-cresolphthalein complexone & 79.65 & 73.76 \\
\hline & Alizarin & 0.16 & 0.16 \\
\hline & Arsenazo III dye & 15.06 & 16.15 \\
\hline & Methyl xylenol method & 1.92 & 2.17 \\
\hline & ISE & 1.60 & 1.24 \\
\hline & Others & 1.28 & 1.55 \\
\hline \multirow[t]{5}{*}{ Uric acid } & Phosphotungstate & 0.10 & 0.09 \\
\hline & Uricase, colorimetry & 97.86 & 97.31 \\
\hline & Iron reduction & 0.10 & 0.09 \\
\hline & Oxygen rate & 0.68 & 0.46 \\
\hline & Others & 1.26 & 2.04 \\
\hline
\end{tabular}

(Continued to the next page)
Table 3. Continued

\begin{tabular}{|c|c|c|c|}
\hline \multirow{2}{*}{ Item } & \multirow{2}{*}{ Analytical method } & \multicolumn{2}{|c|}{ Year } \\
\hline & & 2013 & 2014 \\
\hline \multirow[t]{4}{*}{ Albumin } & Dye binding-BCG & 96.73 & 96.89 \\
\hline & $\begin{array}{l}\text { Dye binding-BCG with } \\
\text { absorbance }\end{array}$ & 1.29 & 1.23 \\
\hline & Dye binding-bromcresol purple & 0.95 & 0.82 \\
\hline & Others & 1.03 & 1.06 \\
\hline \multirow[t]{7}{*}{ Creatinine } & $\begin{array}{l}\text { Jaffe, endpoint without Lloyd } \\
\text { reagent }\end{array}$ & 7.15 & 8.29 \\
\hline & $\begin{array}{l}\text { Jaffe, endpoint with Lloyd } \\
\text { reagent }\end{array}$ & 0.33 & 0.31 \\
\hline & Jaffe, kinetic & 72.80 & 70.88 \\
\hline & Enzymatic & 3.45 & 3.72 \\
\hline & Jaffe, rate-blanked & 12.57 & 12.70 \\
\hline & Jaffe, compensated kinetic & 1.97 & 2.09 \\
\hline & Others & 1.64 & 1.94 \\
\hline \multirow[t]{3}{*}{ Total protein } & Biuret iron reduction & 99.22 & 98.93 \\
\hline & Refractometry oxygen rate & 0.00 & 0.00 \\
\hline & Others & 0.78 & 1.07 \\
\hline \multirow[t]{13}{*}{ Bilirubin } & Evelyn-Malloy+blank & 11.37 & 11.65 \\
\hline & Jendrassik-Grof+blank & 3.01 & 1.31 \\
\hline & Evelyn-Malloy-blank & 6.29 & 6.15 \\
\hline & DMSO+blank & 3.53 & 3.36 \\
\hline & DMSO-blank & 0.26 & 0.25 \\
\hline & Diazonium ion+blank & 20.93 & 21.16 \\
\hline & Diazonium ion-blank & 3.96 & 3.61 \\
\hline & Jendrassik-Grof-blank & 3.01 & 2.79 \\
\hline & Diazonium salt-dyphylline & 1.46 & 1.72 \\
\hline & Bilirubin oxidase & 4.39 & 3.45 \\
\hline & Oxidation & 10.34 & 9.93 \\
\hline & Vanadate oxidation & 30.06 & 31.34 \\
\hline & Others & 3.01 & 3.28 \\
\hline \multirow{3}{*}{$\begin{array}{l}\text { Total } \\
\text { cholesterol }\end{array}$} & Enzymatic & 98.44 & 98.14 \\
\hline & Infra-red chromophore & 0.08 & 0.00 \\
\hline & Others & 1.48 & 1.86 \\
\hline \multirow[t]{6}{*}{ Triglyceride } & 340 nm GPD-Gly & 1.50 & 0.39 \\
\hline & 366 nm GPD-Gly & 0.00 & 0.00 \\
\hline & 500 nm GPD-Gly & 1.09 & 1.26 \\
\hline & Colorimetric-Gly & 4.42 & 4.25 \\
\hline & GPO-Gly & 45.58 & 45.68 \\
\hline & GPO+Gly & 30.05 & 27.75 \\
\hline
\end{tabular}

(Continued to the next page) 
Journal of LABORATORY MEDICINE and QUALITY ASSURANCE

Sun Hee Jun et al • Annual Report of the K-EQAS for Clinical Chemistry (2014)

Table 3. Continued

\begin{tabular}{|c|c|c|c|}
\hline \multirow{2}{*}{ Item } & \multirow{2}{*}{ Analytical method } & \multicolumn{2}{|c|}{ Year } \\
\hline & & 2013 & 2014 \\
\hline & $\begin{array}{l}\text { N-(2-hydroxy-3-sulfopropyl)- } \\
\text { 3,5-dimethoxyanilline+Gly }\end{array}$ & 10.77 & 10.53 \\
\hline & Colorimetric+Gly & 0.25 & 0.08 \\
\hline & Other method & 2.25 & 2.44 \\
\hline \multirow[t]{6}{*}{ AST } & $\mathrm{UV}+\mathrm{P} 5 \mathrm{P}$ & 1.38 & 1.22 \\
\hline & UV-P5P & 93.28 & 93.12 \\
\hline & Dinitrophenylhydrazine & 0.08 & 0.23 \\
\hline & Enzymatic, colorimetry & 0.97 & 0.84 \\
\hline & NADH depletion & 1.13 & 1.15 \\
\hline & Others & 2.91 & 3.28 \\
\hline \multirow[t]{6}{*}{ ALT } & $\mathrm{UV}+\mathrm{P} 5 \mathrm{P}$ & 1.46 & 1.22 \\
\hline & UV-P5P & 93.13 & 93.12 \\
\hline & Dinitrophenylhydrazine & 0.16 & 0.23 \\
\hline & Enzymatic, colorimetry & 0.97 & 0.84 \\
\hline & NADH depletion & 1.05 & 1.15 \\
\hline & Others & 2.99 & 3.28 \\
\hline \multirow{5}{*}{$\begin{array}{l}\text { Alkaline } \\
\text { phosphatase }\end{array}$} & 4-Aminoantipyrine & 0.27 & 0.25 \\
\hline & $\begin{array}{l}\text { P-NPP, diethanolamine } \\
\text { (German Society for Clinical } \\
\text { Chemistry) }\end{array}$ & 19.12 & 18.64 \\
\hline & $\begin{array}{l}\text { P-NPP, 2-amino-2-methyl-1- } \\
\text { propanol (IFCC) }\end{array}$ & 46.32 & 48.00 \\
\hline & P-NPP, 2-ethylaminoethanol & 31.51 & 29.87 \\
\hline & Others & 2.78 & 3.23 \\
\hline \multirow{6}{*}{$\begin{array}{l}\text { Lactate } \\
\text { dehydrogenase }\end{array}$} & Dinitrophenylhydrazine & 0.60 & 0.46 \\
\hline & Lactate to pyruvate & 41.98 & 42.49 \\
\hline & Pyruvate to lactate & 54.89 & 53.93 \\
\hline & Tetrazolium & 0.12 & 0.12 \\
\hline & Dry chemistry & 1.21 & 1.04 \\
\hline & Others & 1.21 & 1.96 \\
\hline \multirow{5}{*}{$\begin{array}{l}\text { Gamma } \\
\text { glutamyl } \\
\text { transferase }\end{array}$} & GGCNA (IFCC, $37^{\circ} \mathrm{C}$ ) & 80.53 & 81.55 \\
\hline & GGPNA $\left(37^{\circ} \mathrm{C}\right)$ & 12.92 & 11.88 \\
\hline & $\begin{array}{l}\text { GGCNA (Japan Society of } \\
\text { Clinical Chemistry) }\end{array}$ & 2.07 & 2.19 \\
\hline & Dry chemistry & 0.99 & 1.02 \\
\hline & Others & 3.48 & 3.36 \\
\hline \multirow{2}{*}{$\begin{array}{l}\text { HDL } \\
\text { cholesterol }\end{array}$} & Direct homogeneous & & 6.59 \\
\hline & Beckman & & 8.89 \\
\hline
\end{tabular}

(Continued to the next page)
Table 3. Continued

\begin{tabular}{llr}
\hline \multirow{2}{*}{ Item } & & \multicolumn{2}{c}{ Year } \\
\cline { 3 - 3 } & Denka & 2014 \\
\hline & Kyowa & 6.79 \\
& Roche & 8.32 \\
& Sekisui & 13.67 \\
& Siemens & 22.08 \\
Siemens-ADVIA & 0.67 \\
Wako & 3.25 \\
Randox & 7.07 \\
Direct method & 0.57 \\
Other & 17.88 \\
cholesterol & & 4.21 \\
& Kenka & 2.09 \\
& Kyowa & \\
Roche & Sekisui & 10.01 \\
Siemens & 20.58 \\
Siemens-ADVIA & 22.95 \\
Wako & 0.70 \\
Randox & 5.01 \\
Direct method & 6.68 \\
& & 1.25 \\
& & 30.74 \\
\hline
\end{tabular}

Abbreviations: ISE, ion-selective electrodes; GOD, glucose oxidase; G6PD, glucose-6-phophate dehydrogenase; UV, ultra violet; BCG, bromcresol green; DMSO, dimethyl sulfoxide; GPD, glycerol phosphate dehydrogenase; Gly, glycerol; GPO-Gly, glycerol phosphate oxidase without glycerol blank; GPO+Gly, glycerol phosphate oxidase with glycerol blank; P5P, pyridoxal-5-phosphate; $\mathrm{NADH}$, nicotinamide adenine dinucleotide dehydrogenase; P-NPP, para nitrophenylphosphate; IFCC, International Federation of Clinical Chemistry; GGCNA, gamma-glutamyl-carboxynitroanilide; GGPNA, gamma-glutamyl-p-nitroanilide.

다양한 방법들이 분포되어 있었다.

측정방법에 있어서는 전체적으로 전년도와 큰 차이는 없 지만[5], 측정방법에서 한가지 원리가 전체의 $90 \%$ 를 넘 는 항목을 살펴보면 blood urea nitrogen은 urease with glutamate dehydrogenase법이 96.31\%, 요산은 uricase를 이용한 비색법이 $97.31 \%$, 단백은 Biuret법이 $98.93 \%$, 알부 민은 bromcresol green법이 $97.96 \%$, 총 콜레스테롤은 효소 비색법이 98.14\%, AST 및 ALT는 ultra violet-pyridoxal-5phosphate법이 약 $93.12 \%$ 로 나타났다(Table 3).

변이계수는 측정방법별 및 검사항목별(Tables 4,5$)$ 과 연도 
Journal of LABORATORY MEDICINE and QUALITY ASSURANCE

Sun Hee Jun et al • Annual Report of the K-EQAS for Clinical Chemistry (2014)

Table 4. CVs (\%) according to the test items by principle in 2014

\begin{tabular}{|c|c|c|}
\hline Item & Principle & $\mathrm{CV}(\%)$ \\
\hline \multirow[t]{3}{*}{ Sodium } & ISE, diluted (indirect) & 1.33 \\
\hline & ISE, undiluted (direct) & 1.93 \\
\hline & Other method & 2.10 \\
\hline \multirow[t]{3}{*}{ Potassium } & ISE, diluted (indirect) & 2.08 \\
\hline & ISE, undiluted (direct) & 3.18 \\
\hline & Other method & 2.96 \\
\hline \multirow[t]{3}{*}{ Chloride } & ISE, diluted (indirect) & 2.51 \\
\hline & ISE, undiluted (direct) & 3.00 \\
\hline & Other method & 3.28 \\
\hline \multirow{3}{*}{$\begin{array}{c}\text { Blood urea } \\
\text { nitrogen }\end{array}$} & Urease with glutamate dehydrogenase & 5.01 \\
\hline & Urease-indophenol (Berthelot) & 6.06 \\
\hline & Other method & 14.52 \\
\hline \multirow[t]{3}{*}{ Glucose } & Glucose oxidase (colorimetric) & 4.37 \\
\hline & Hexokinase, UV & 3.02 \\
\hline & Glucose dehydrogenase & 4.62 \\
\hline \multirow[t]{3}{*}{ Total calcium } & Arsenazo III dye & 3.03 \\
\hline & Cresolphthalein complexone & 2.97 \\
\hline & ISE, diluted & 3.12 \\
\hline \multirow[t]{3}{*}{ Phosphorous } & Phosphomolybdate, UV & 4.00 \\
\hline & Phosphomolybdate reduction & 3.86 \\
\hline & Other method & 7.30 \\
\hline \multirow[t]{4}{*}{ Creatinine } & Jaffe, kinetic & 7.78 \\
\hline & Jaffe, rate-blanked & 4.23 \\
\hline & Jaffe, endpoint-Lloyd & 7.48 \\
\hline & Enzymatic & 8.70 \\
\hline \multirow[t]{7}{*}{ Total bilirubin } & Evelyn-Malloy+blank & 8.71 \\
\hline & Evelyn-Malloy-blank & 12.11 \\
\hline & Diazonium ion+blank & 8.73 \\
\hline & Diazonium ion-blank & 11.83 \\
\hline & Oxidation & 6.56 \\
\hline & Vanadate oxidation & 6.03 \\
\hline & Other method & 20.16 \\
\hline \multirow[t]{2}{*}{ Uric acid } & Uricase & 3.93 \\
\hline & Other method & 15.96 \\
\hline \multirow[t]{2}{*}{ Total protein } & Biuret method & 3.68 \\
\hline & Other method & 7.38 \\
\hline \multirow[t]{3}{*}{ Albumin } & Dye binding-BCG & 4.36 \\
\hline & Dye binding-BCG+absorbance & 4.27 \\
\hline & Other method & 7.73 \\
\hline
\end{tabular}

(Continued to the next page)
Table 4. Continued

\begin{tabular}{|c|c|c|}
\hline Item & Principle & $\mathrm{CV}(\%)$ \\
\hline \multirow{2}{*}{$\begin{array}{l}\text { Total } \\
\text { cholesterol }\end{array}$} & Enzymatic & 3.83 \\
\hline & Other method & 10.62 \\
\hline \multirow[t]{5}{*}{ Triglyceride } & GPO-Gly & 6.29 \\
\hline & GPO+Gly & 8.18 \\
\hline & $\begin{array}{l}\text { N-(2-hydroxy-3-sulfopropyl)-3,5- } \\
\text { dimethoxyanilline+Gly }\end{array}$ & 8.18 \\
\hline & $\begin{array}{l}340 \text { nm glycerol phosphate } \\
\text { dehydrogenase-Gly }\end{array}$ & 15.40 \\
\hline & Colorimetric-Gly & 6.19 \\
\hline \multirow[t]{3}{*}{ AST } & UV without P5P & 5.41 \\
\hline & UV with P5P & 6.60 \\
\hline & Enzymatic-vitros & 4.17 \\
\hline \multirow[t]{3}{*}{ ALT } & UV without P5P & 6.28 \\
\hline & UV with P5P & 9.69 \\
\hline & Enzymatic-vitros & 5.97 \\
\hline \multirow[t]{3}{*}{$\begin{array}{l}\text { Alkaline } \\
\text { phosphatase }\end{array}$} & $\begin{array}{l}\text { PNPP, 2-amino-2-methyl-1-propanol } \\
\text { buffer }\end{array}$ & 16.11 \\
\hline & PNPP, diethanolamine buffer & 16.98 \\
\hline & PNPP, 2-ethylaminoethanol buffer & 6.86 \\
\hline \multirow{4}{*}{$\begin{array}{l}\text { Lactate } \\
\text { dehydrogenase }\end{array}$} & Lactate to pyruvate & 6.03 \\
\hline & Pyruvate to lactate & 7.01 \\
\hline & Dry chemistry & 10.62 \\
\hline & Other method & 38.23 \\
\hline \multirow[t]{3}{*}{$\begin{array}{l}\text { Gamma } \\
\text { glutamyl } \\
\text { transferase }\end{array}$} & $\begin{array}{l}\text { Gamma-glutamyl-carboxy-nitroanilide } \\
\text { (International Federation of Clinical } \\
\text { Chemistry, } 37^{\circ} \mathrm{C} \text { ) }\end{array}$ & 5.88 \\
\hline & Gamma-glutamyl-p-nitroanilide $\left(37^{\circ} \mathrm{C}\right)$ & 7.83 \\
\hline & Dry chemistry & 5.03 \\
\hline \multirow{10}{*}{$\begin{array}{l}\text { HDL } \\
\text { cholesterol }\end{array}$} & Direct homogeneous & 14.26 \\
\hline & Beckman & 5.45 \\
\hline & Denka & 12.21 \\
\hline & Kyowa & 8.18 \\
\hline & Roche & 6.03 \\
\hline & Sekisui & 5.23 \\
\hline & Siemens-ADVIA & 3.72 \\
\hline & Wako & 9.62 \\
\hline & Randox & 18.11 \\
\hline & Direct method & 13.34 \\
\hline
\end{tabular}


Table 4. Continued

\begin{tabular}{llc}
\hline \multicolumn{1}{c}{ Item } & \multicolumn{1}{c}{ Principle } & CV (\%) \\
\hline $\begin{array}{l}\text { LDL } \\
\text { cholesterol }\end{array}$ & Denka & 16.87 \\
& Kyowa & 5.91 \\
& Roche & 7.40 \\
& Sekisui & 5.60 \\
& Siemens & 17.32 \\
& Siemens-ADVIA & 5.27 \\
& Wako & 9.46 \\
& Randox & 16.49 \\
& Direct method & 16.54 \\
\hline
\end{tabular}

Abbreviations: ISE, ion-selective electrodes; UV, ultra violet; $\mathrm{BCG}$, bromcresol green; GPO-Gly, glycerol phosphate oxidase with glycerol blank; GPO+Gly, glycerol phosphate oxidase without glycerol blank; P5P, pyridoxal-5-phosphate; PNPP, para nitrophenylphosphate.

별 변이계수를 표시하였다(Table 6). 측정방법별에서 보면 대 부분의 방법별 변이계수가 $10 \%$ 이내로 나타났지만 alkaline phosphatase나 lactate dehydrogenase, total bilirubin 등 의 일부 방법에서 $10 \%$ 이상의 높은 변이계수를 보이고 있다. 중성지방은 검체의 기질에 영향을 가장 많이 검사종목이어 서 peer group별로 결과에 많은 차이를 보이기 때문에 올바른 peer group 선택이 중요하다. 2013년부터 각 기관에서 정확한 검사방법 선택의 중요성을 인지하고 올바른 peer group을 선 택하였기 때문에 방법별 변이계수의 지속적 향상을 보이고 있 다고 생각된다. 이런 검체의 기질에 따른 결과차이는 2011년 처음으로 도입한 정확도 기반 신빙도조사를 시행함으로써 해 결될 것으로 생각된다.

2012년도부터 혈액가스의 분석은 기기회사와 기기별로 분 류하여 peer group을 좀 더 세분화하여 평가하였다(Table 7). $\mathrm{pH}$ 의 변이계수에 비해 $\mathrm{pCO}_{2}, \mathrm{pO}_{2}$ 의 변이계수는 약간 높은 경 향을 보이지만 전체적으로 안정된 결과를 보여주고 있다.

\section{임상화학분과위원회 위원(2014)}

송정한(위원장, 서울대학교 의과대학), 전선희(간사, 분당서

Table 5. Peer-group CVs (\%) according to test and trials in 2014

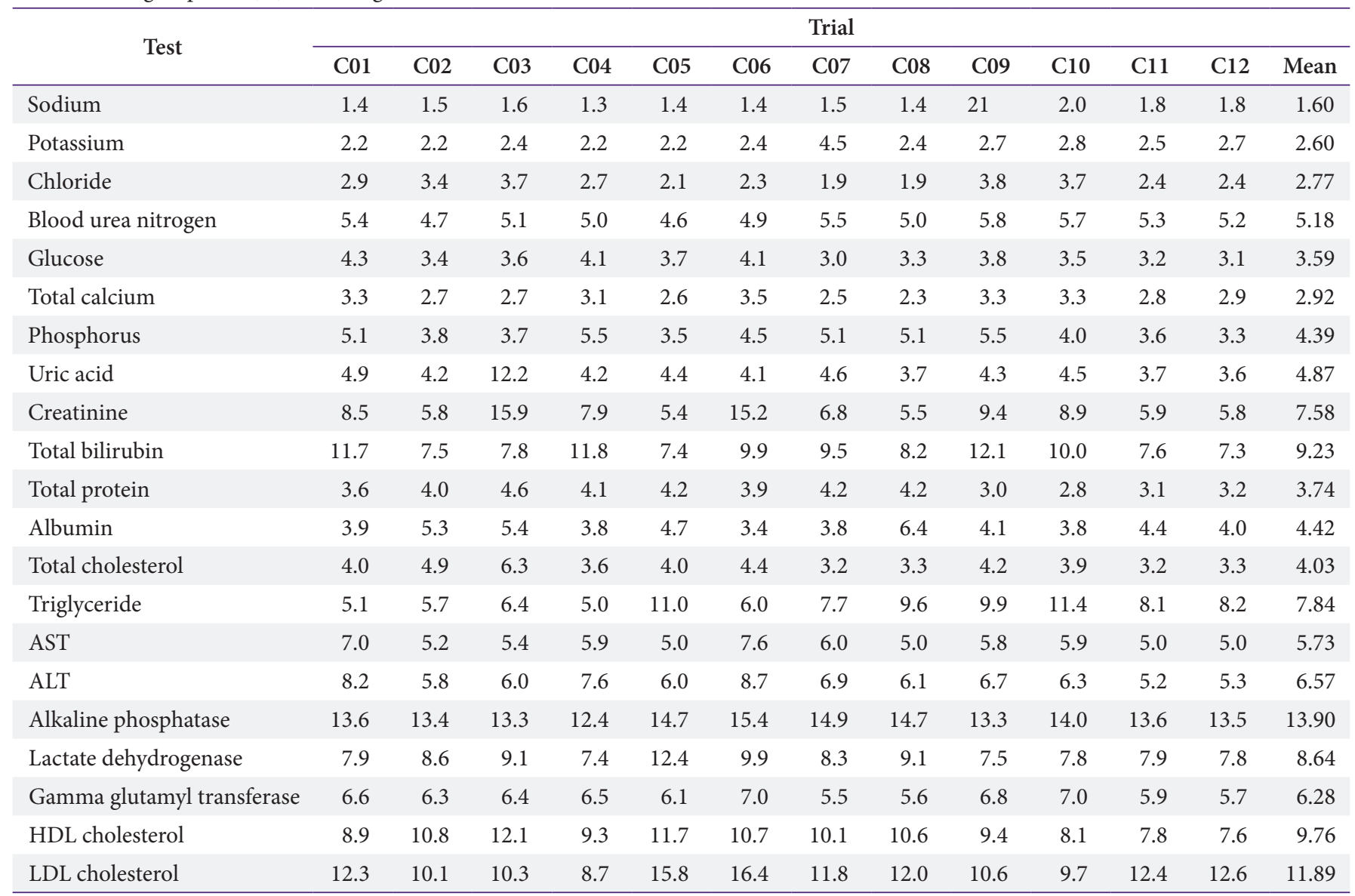


Table 6. Annual changes in CVs (\%) according to test

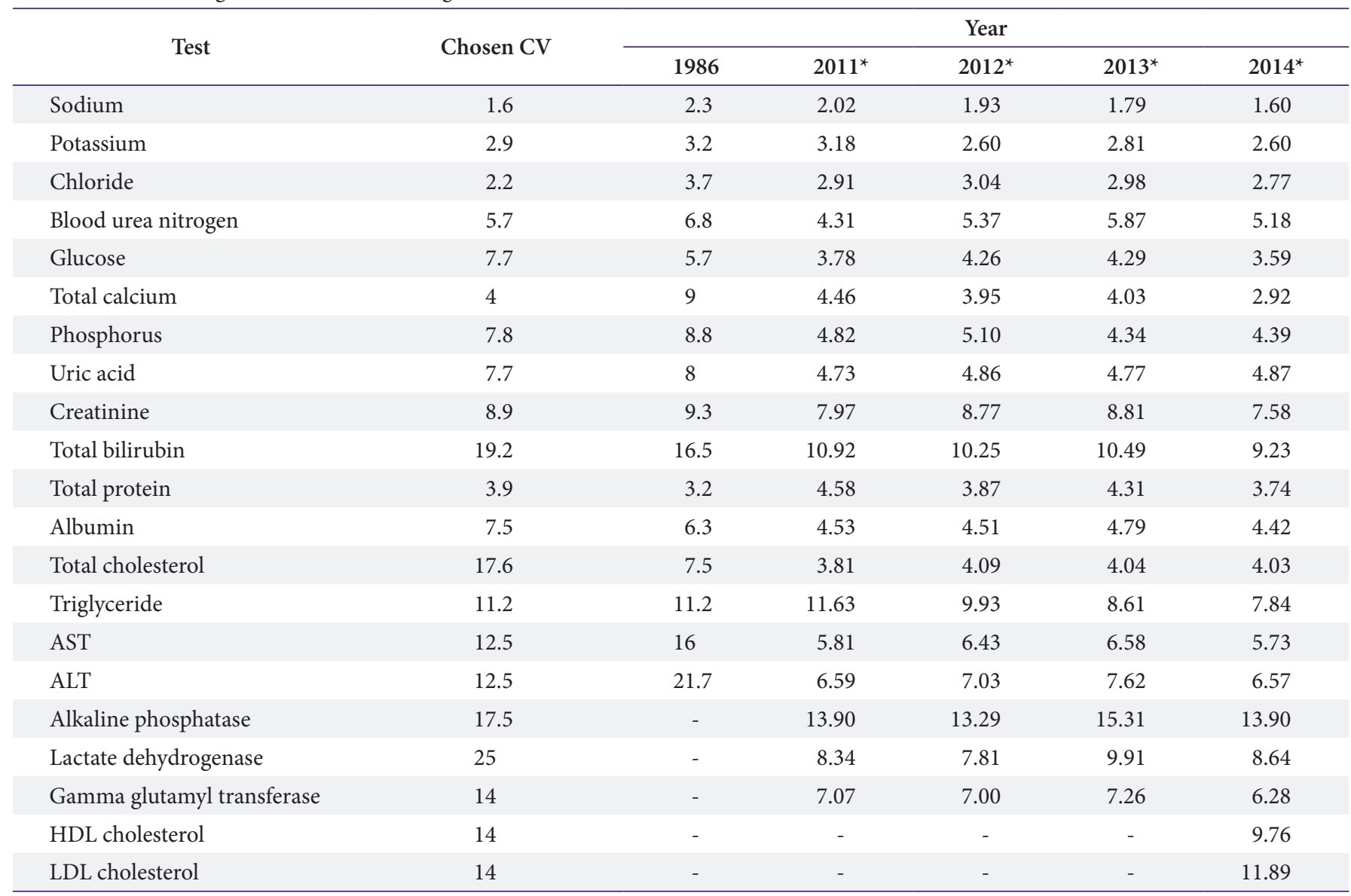

${ }^{\star}$ Peer group coefficients of variation.

Table 7. CVs (\%) according to test for blood gas (2014)

\begin{tabular}{|c|c|c|c|c|c|c|}
\hline Code & Manufacturer & Code & Instrument group & $\mathrm{pH}$ & $\begin{array}{l}\text { Partial pressure of } \\
\text { carbon dioxide }\end{array}$ & $\begin{array}{c}\text { Partial pressure } \\
\text { of oxygen }\end{array}$ \\
\hline 270 & OPTI Medical Systems & 01 & OPTI-CCA & 0.62 & 8.55 & 14.16 \\
\hline \multirow[t]{4}{*}{380} & Siemens Healthcare & 01 & RAPIDlab 248/348 & 0.44 & 10.67 & 11.93 \\
\hline & & 02 & RAPIDlab 800 Series & 0.27 & 11.87 & 12.67 \\
\hline & & 03 & Rapidpoint 400 Series & 0.22 & 10.04 & 12.89 \\
\hline & & 04 & RAPIDlab 1200 Series & 0.2 & 7.26 & 7.7 \\
\hline 760 & Medica & 01 & EasyBloodGas & 0.29 & 5.2 & 10.21 \\
\hline \multirow[t]{3}{*}{780} & NOVA Biomedical & 01 & Phox group & 0.92 & 16.88 & 13.26 \\
\hline & & 02 & pHOx+ & 1.15 & 15.26 & 10.44 \\
\hline & & 03 & CCX group & 0.17 & 7.81 & 5.91 \\
\hline 840 & Radiometer & 01 & Electrode & 0.12 & 8.92 & 6.62 \\
\hline \multirow[t]{2}{*}{880} & Roche Diagnostics & 01 & Cobas b 121 (Roche OMNI C) & 0.24 & 6.9 & 9.33 \\
\hline & & 02 & Cobas b 221 (Roche OMNI S) & 0.19 & 6.16 & 9.2 \\
\hline 970 & Instrumentation Laboratory & 01 & GEM Premier 3000 & 0.23 & 8.02 & 7.5 \\
\hline
\end{tabular}

OPTI Medical Systems, Roswell, GA, USA; Siemens Healthcare, Erlangen, Germany; Medica, Bedford, MA, USA; NOVA Biomedical, Waltham, MA, USA; Radiometer, Copenhagen, Denmark; Roche Diagnostics, Basel, Switzerland; Instrumentation Laboratory, Lexington, MA, USA. 
Journal of LABORATORY MEDICINE and QUALITY ASSURANCE

Sun Hee Jun et al • Annual Report of the K-EQAS for Clinical Chemistry (2014)

울대학교병원), 장호은(분당서울대학교병원), 민원기(울산대 학교 의과대학), 김정호(연세대학교 의과대학), 박일규(한양 대학교 의과대학), 이도훈(국립암센터), 이수연(성균관대학교 의과대학), 전사일(울산대학교 의과대학), 한태진(서울아산병 원), 홍기숙(이화여자대학교 의과대학)

\section{REFERENCES}

1. Tchai BS, Cho HI, Kim SI, Park MH, Moon YH, Cho WH, et al. Report on quality assessment of clinical chemistry in Korea 1978-1980. J Lab Med Qual Assur 1981;3-15.

2. Min WK, Ko C, Kim KD, Kim YK, Kim JH, Kim JQ, et al. Annual report on external quality assessment in clinical chemistry in Korea (2008). J Lab Med Qual Assur
2009;31:1-12.

3. Min WK, Ko C, Kim KD, Kim YK, Kim JH, Kim JQ, et al. Annual report on external quality assessment in clinical chemistry in Korea (2009). J Lab Med Qual Assur 2010;32:1-10.

4. Song J, Kwon KC, Kim JH, Kim JW, Min WK, Lee SY, et al. Annual report on external quality assessment in metabolic disorders in Korea (2009). J Lab Med Qual Assur 2010;32:131-46.

5. Jun SH, Song J, Clinical Chemistry Subcommittee, The Korean Association of Quality Assurance for Clinical Laboratory. Annual report on the external quality assessment scheme in clinical chemistry (2013). J Lab Med Qual Assur 2014;36:113-21.
임상화학검사 신빙도조사 결과보고(2014)

\section{전선희 - 송정한 - 대한임상검사정도관리협회 임상화학분과위원회}

서울대학교 의과대학 분당서울대학교병원 진단검사의학교실

2014년에는 일반화학 1,355 개 기관 및 혈액가스 480 개 기관을 대상으로 일반화학 21종목, 혈액 가스 3종목에 대하여 4월부터 11월까지 일반화학 4회, 혈액가스 2 회, 각 회차당 3 가지 검체를 이용 하여 신빙도조사를 시행하였다. 정도관리물질은 1년분을 연초에 한 번에 발송하였다. 평균 응답률 은 일반화학이 $93.4 \%$, 혈액가스가 $90.0 \%$ 였다. 각 기관이 직접 검사방법과 결과를 홈페이지에 입 력하게 되면 평가일 이후 검사종목별 검사방법에 따른 평균, 표준편차, 변이계수 등을 분석한 방법별 통계분석자료와, 각 기관의 항목별 평균, 표준편차, 동일방법 참가기관 수, 표준편차지수(standard deviation index), 동일방법에 속한 peer group별 변동지수점수법(variance index score, VIS) 등 과 각 항목별 누적 VIS의 분포표가 있는 기관별 통계분석자료가 출력되도록 하였다. 임상화학 분야의 검사를 실시하는 각 검사실에서는 지속적인 신빙도조사사업 참여를 통해 검사의 질을 높여나가야 할 것으로 생각되었다.

(J Lab Med Qual Assur 2015;37:115-123)

교신저자: 송정한

우)13620 경기도 성남시 분당구 구미로 173번길 82, 서울대학교 의과대학 분당서울대학교병원 진단검사의학교실

Tel: 031)787-7691, Fax: 031)787-4015, E-mail: songjhcp@snu.ac.kr

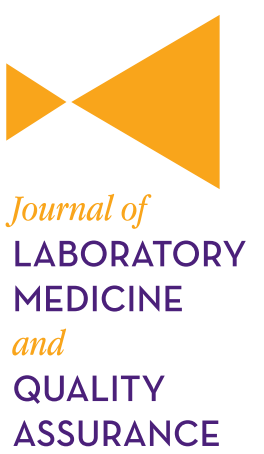

ASSURANCE 